\title{
Structural, Thermal, Optical Characterizations of PANI/PMMA Composite Doped by TiO2 as an Application in Optoelectronic Devices
}

\section{Q. A. Alsulami}

King Abdulaziz University
A. A. Rajeh ( $\square$ a.rajeh88@yahoo.com )
Amran University https://orcid.org/0000-0002-5789-0599

\section{Research Article}

Keywords: PANI/PMMA blend, TiO2 nanoparticles, Thermal properties, Optical characteristics, Band-gap.

Posted Date: June 28th, 2021

DOl: https://doi.org/10.21203/rs.3.rs-638653/v1

License: (c) (1) This work is licensed under a Creative Commons Attribution 4.0 International License.

Read Full License 
Structural, thermal, optical characterizations of PANI/PMMA composite doped by $\mathrm{TiO}_{2}$ as an application in optoelectronic devices

\author{
Q. A. Alsulami ${ }^{a}$, A. Rajeh $^{\text {** }}$ \\ ${ }^{\text {a }}$ Chemistry Department, Faculty of Science, King Abdulaziz University, P.O. Box 80203, Jeddah 21589, Saudi Arabia \\ ${ }^{\mathrm{b}}$ Physics Department, Faculty of Science, Amran University, Yemen
}

\begin{abstract}
The casting method was employed for the preparation of polymer blend films doped with $\mathrm{TiO}_{2}\left(0.5,1,1.5\right.$, and 2.3 wt.\%). The XRD outcomes show that $\mathrm{TiO}_{2}$ phase formation is anatase, with an average crystal size of $20.25 \mathrm{~nm}$. PANI/PMMA-TiO ${ }_{2}$ nanocomposites samples have an amorphous nature. In addition, the degree of amorphousity is increased with the increase of the content of the $\mathrm{TiO}_{2}$ NPs. The FTIR method was employed for presenting the vibrational bands of the nanocomposites and the intermolecular bonding of the blend with the $\mathrm{TiO}_{2}$ NPs. The applied investigation involved the optical constant like absorption as well as t90-etransmission spectra, refractive index, reflectance, coefficient extinction, dielectric constant' imaginary and real parts, the susceptibility $\left(\chi^{3}\right)$ of third order and the optical band gaps. The optical band gap $\left(E_{g}\right)$ values of the films of fabricated nanocomposites was lower upon doping ( $\leq 1.5 \mathrm{wt} \%$ ). The reduction of the value happened due to the introduction of the preselected $\mathrm{TiO}_{2} \mathrm{NPs}_{\text {into }}$ thin films. Such values significantly match the values which were revealed by the Tauc technique. It was proved through DSC and TGA techniques that $\mathrm{TiO}_{2}$ NPs can lead to the enhancement of the polymer blend in terms of thermal stability. As displayed by the DSC analysis, there is a single $\mathrm{Tg}$ of the polymer blend (PANI/PMMA), which prove their miscibility. The optical constants displayed by the experimental results show noticeable changes upon raising the doping concentrations. The resultant doped thin films indicate that the fabricating high-efficient optoelectronic machines are greatly promising.
\end{abstract}

Keywords: PANI/PMMA blend; $\mathrm{TiO}_{2}$ nanoparticles; Thermal properties; Optical characteristics; Band-gap.

* Corresponding author: A. Rajeh (a.rajeh88@yahoo.com) 


\section{Introduction}

The easy processability and low cost of polymers are probably the reason behind their dominance and prevalence as materials [1,2]. The prospective of combining the attractive functionalities of organic polymers and inorganic nanoparticles for enhancing their synergistical characteristics has recently attracted the attention of researchers to polymer blends doped with nanoparticles. The resultant nanocomposites have several applications in aerospace, automotive, optoelectronics [3]. The particle properties including the size, shape, loading, interfacial bonding, and dispersion of the fillers influence the characteristics of polymer composites [3,4]. Many properties of polymer matrix can be enhanced by inorganic particles as fillers including its thermal, mechanical, electronic, magnetic, optical characteristics as well as its density, and refractive index [5]. The main polymer used for polymer sensors and polymer optical fiber fabrication (POF) is Polymethyl methacrylate (PMMA). The structural and optical characteristics of the polymer may change upon doping nanoparticles within its main chains [4]. The use of PMMA, polyvinyl alchohol (PVA) and polyethylene oxide (PEO) is common in optical fiber fabrication, particularly in the core [6-8]. Better optical and electrical characteristics of polymers as a result of doping them with rare earth elements (REE) especially PMMA have been reported by many studies [9]. In recent times, several research groups are interested in the studying the impact of the addition of REE with nanosized particles as it can result in changing the properties of the polymer [10]. There are many advantages that can result from doping PMMA with nanoparticles. One advantages of this procedure is producing corrosion-resistant conductive materials[11]. George et al made a record of a change in a polymer's main chain, such as single and double bonds variations [12], which permits the electrons delocalization in the polymer matrix [13]. The effect of adding nano $\mathrm{ZnO}$ particles within the main chain of PMMA was investigated by Soumya et al [11]. The advantages of the doping of nanoparticles within PMMA can be seen in the change that occurs in the different characteristics of the polymer composites[14]. The change in optical and structural characteristics happen as a result of doping the nanoparticles within the polymer main chains. The higher conductivity, cost-effectiveness, easy synthesis, and environmental stability of polyaniline (PANI) makes it more attractive than the other conducting polymers $[15,16]$. Yet, PANI is poor in terms of thermal stability, solubility, 
and mechanical characteristics. PANI can be appropriately combined with metal nanoparticles due to its functional group. This can lead to an extra enhancement in its electrical conductivity and thermal stability. The effective interaction that can result from combining metal nanoparticles with functional groups with PANI will lead to improving the conductivity and optical characteristics. Thus, the resultant polymer blend (PANI/PMMA) demonstrates excellent characteristics of optical device applications. In addition, researchers and technologists have been interested in the study and production of nanosize material, particularly, with mounting their applications in optical and electronics manufacturing[17,18]. The procedure of consolidating PMMA, PANI, and metal nanocomposites can assist in the formation of new materials with enhanced optical and structural characteristics [19]. The various traits of Titanium dioxide including its high index of refractive as well as its low cost, chemical stability, nontoxicity, hydrophilicity, high photocatalytic characteristics makes it one of the best semiconductor ceramic material. The physical and chemical characteristics of $\mathrm{TiO} 2$ makes it very useful in several applications. These applications include supercapacitors, dye-sensitized solar cells, quantum-dot-sensitized solar cells, photoelectrolysis, biosensors, antimicrobical activity photochromic machines, selfcleaning, gas sensor and antireflective coatings [20,21]. The various crystal phases (anatase, rutile, and brookite) of $\mathrm{TiO}_{2}$ rely on the conditions and the method of preparation. There are various methods that can be utilized for synthesizing TiO2 NPs. These methods include spin coating, chemical vapor deposition, atomic layer deposition, electrospray deposition and molecular beam epitaxy [22,23]. There is also the sol-gel technique which has several advantages including high homogeneity for forming nano structures with high-quality and its applicability in simple equipment at low temperature [24]. This work aims at preparing new and flexible PANI/PMMA/TiO2 nanocomposites films made from insulating and conducting polymers. It also aims at investigating the structural, thermal and optical characteristics of these films. The changes which have been reported in PANI/PMMA/TiO2 nanostructured films in terms of the optical bandgap (Eg), absorption edge $(\mathrm{Ed})$, refractive index $(\mathrm{n})$, extinction coefficient $(\mathrm{K})$, dielectric characteristics, and optical conductivity ( $\sigma o p t)$ can make it very useful in several 
applications including bio and chemical sensors, catalysis and as an active layer of optoelectronic machines.

\section{Experimental details}

\subsection{Materials}

Poly (methyl methacrylate) (PMMA) with MW=100,000 was purchased from BDH chemicals, England. Double distillation was used to purify aniline (Merck). Ammonium per sulfate (APS) was purchased from Merck, Germany. Dimethyl formamide (DMF) was provided from Sigma-Aldrich. The preparation process for titanium dioxide nanoparticles was explained in a previous work[25].

\subsection{Synthesis of PANI}

The technique of chemical oxidative polymerization was used to synthesize PANI at $0{ }^{\circ} \mathrm{C}$ to $5{ }^{\circ} \mathrm{C}$ as mentioned earlier[26]. The procedure involved mixing $9 \mathrm{mmol}$ aniline with 50 $\mathrm{mL}$ of $1 \mathrm{M} \mathrm{HCl}$ solution and sufficient stirring, then, adding APS to it in order to start the reaction of polymerization (the mole ratio of aniline: APS $=1: 1$ ). This polymerization procedure was conducted at $0 \circ \mathrm{C}$ for 10 hours with continuous stirring. After that, the resultant polymer was rinsed and cleaned several times using deionized water, ethanol, dilute $\mathrm{HCl}$, and acetone and was finally dried at $60{ }^{\circ} \mathrm{C}$ for 6 hours.

\subsection{Samples preparation}

PANI/PMMA (20/80 wt.\%) was added to DMF and stirred using a stable temperature magnetic stirring at $75^{\circ} \mathrm{C}$. Variable quantities of $\mathrm{TiO}_{2}(0-1.2$ wt.\%) were added to the prepared solution. The solutions of these samples were submerged in ultrasonic for 1 hour to achieve a homogeneous mixture of filled samples and to increase the suspension of $\mathrm{TiO}_{2}$ NPs. The different $\mathrm{TiO}_{2}$ content samples were distributed in Petri dishes and dried in a $70^{\circ} \mathrm{C}$ oven for 48 hours. Following that, samples were husked from Petri dishes and under vacuum-stored. The resulting films were analyzed visually for their dryness and free standing nature. The electrolytes have a thickness ranging from 0.1 to $0.5 \mathrm{~mm}$. 


\subsection{Measurements}

The XRD patterns were determined using a Diano USA X-ray diffractometer with $\mathrm{Cu} \mathrm{Ka}$ radiation at $\mathrm{k}=1.54 \mathrm{~A}$ and voltage is $30 \mathrm{kV}$. Bragg's angle $2 \theta$ has a calculated range of (10-80). At room temperature, all of the prepared samples were subjected to Fourier transform infrared spectroscopy (Nicolet iS10, USA) in the range of $4000-500 \mathrm{~cm}^{-1}$. Thermogravimetric (TGA) curves were measured on a TGA thermal analyzer (STDQ600, USA) in the temperature range $30-600{ }^{\circ} \mathrm{C}$ at a rate of $10{ }^{\circ} \mathrm{C} \min 1$ in a nitrogen atmosphere. Thermodynamic stability of prepared samples scanned with differential scanning calorimetry was investigated (DSC-50, Shimadzu). The transmittance and absorbance spectra of PANI/PMMA/TiO 2 were measured with an accuracy of $0.2 \mathrm{~nm}$ using a Jasco V-670spectrophotometer in the wavelength range 190-2500 nm.

\section{Results and discussion}

\section{1. X-ray diffraction}

As seen in Figure 1, the study of the structure of pure blend PMMA/PANI and its nanocomposites was carried out using X-ray diffraction (XRD). The XRD pattern of $\mathrm{TiO}_{2}$ NPs are displayed in Figure 1a, which also presents the diffraction peaks at $2 \theta$ values of 25.33, 48.01, 54.69, 62.7, and 68.71 corresponding to (101), (200), (105), (213), and (116) lattice planes of $\mathrm{TiO}_{2}$ and ascribing to JCPDS file no. 21-1272.[21]. Furthermore, the Scherrer equation was employed in determining the average size of the particle (D) of the $\mathrm{TiO}_{2}$ [27]. The size of the particle was found to be $20.25 \mathrm{~nm}$. Based on the standard pattern (JCPDS card No. 01-089-0552), all the diffraction peaks were in good agreement with the tetragonal rutile $\mathrm{TiO}_{2}$. Broad and slightly protruded peaks were seen at $14.5^{\circ}$, and $29.8^{\circ}$ as shown in fig. $1 \mathrm{~b}$, which evidences achievement of the polymer blend synthesis and reveals its amorphous nature as well. This peak of pure blend decreases a little and becomes depressed, which clearly indicates the uniform and deep interaction of $\mathrm{TiO}_{2}$ into PMMA/PANi as reflected in the XRD pattern of PMMA/PANI/TiO 2 (Fig. 1 b)[28]. The characteristic peaks related to $\mathrm{TiO}_{2}$ ceased to exist as exhibited by the XRD pattern of $\mathrm{PMMA} / \mathrm{PANI} / \mathrm{TiO}_{2}$ nanocomposite (at concentrations $\leq 1 \mathrm{wt} . \%)$. This proves the existence and effective dispersion of nanofiller 
in the polymer matrix. Yet, the diffraction peaks appearing at $2 \theta=25.4^{\circ}$ [29], at concentrations $\geq 1.5 \mathrm{wt} \%$, are attributed to $\mathrm{TiO}_{2} \mathrm{NPs}$, which increase (intensity) upon raising $\mathrm{TiO}_{2}$ concentration in the nanocomposites films. In addition, the substantial reduction in the amorphous nature of polymer blend in the relation to nanocomposites films (1.5 wt $\%)$, indicate the need for strong interaction to obtain the wanted optical, and thermal characteristics.

\section{2. FTIR spectroscopy}

The vibrational bands of the nanocomposites are studied using Fourier Transform Infrared spectroscopy (FTIR). In the spectral range 4000-500 $\mathrm{cm}^{-1}$, Figure 2 shows the FTIR spectra of pure blend and PANI/PMMA/TiO 2 nanocomposites films. Figure 2 indicates that the peaks between 500 and $800 \mathrm{~cm}^{-1}$ can be attributed to $\mathrm{C}-\mathrm{H}$ bending, while the peaks at 1063 and $1255 \mathrm{~cm}^{-1}$ can be attributed to $-\mathrm{C}-\mathrm{O}-\mathrm{C}-$ and $\mathrm{C}-\mathrm{O}$ bond stretching vibrations, respectively. The bands related to the stretching vibration of N-B-N and $\mathrm{N}=\mathrm{Q}=\mathrm{N}$ structures existed at $1495 \mathrm{~cm}^{-1}$ and $1145 \mathrm{~cm}^{-1}$, respectively, corroborating the production of polyaniline in the polymeric matrices, where $\mathrm{N}=\mathrm{Q}=\mathrm{N}$ was used as a measure of electron delocalization [30]. In addition, the carbonyl group of PMMA is responsible for a significant band at $1735 \mathrm{~cm}-1$. Finally, as shown in Figure 2, the bands that appear in the $3100-2800 \mathrm{~cm}^{-1}$ spectral range correspond to various $\mathrm{CH}_{3}$ and $\mathrm{CH}_{2}$ vibrational modes. $\mathrm{As}^{\mathrm{TiO}_{2}} \mathrm{NPs}$ are inserted into a polymeric matrix, the intensity of the peaks at $689 \mathrm{~cm}-1,753 \mathrm{~cm}^{-1}, 1064 \mathrm{~cm}^{-1}$, and between 1350 and $3600 \mathrm{~cm}^{-1}$ reduces. The interaction or intermolecular bonding between the blend matrix and $\mathrm{TiO}_{2} \mathrm{NPs}$ could explain the significant reduces in peak intensities across the entire FTIR spectrum[4]. The presence of hydrogen bonding between polymer blend and $\mathrm{TiO}_{2} \mathrm{NPs}$ may explain the decrease in peak intensity at $1735 \mathrm{~cm}^{-1}$, as well as a peak position shifted to a lower wavenumber by doping. As a result, the $\mathrm{TiO} 2 \mathrm{NPs}$ doped within the blend are required to contribute to the PMMA backbone structure's carbonyl groups $\mathrm{C}=\mathrm{O}$. This may be due to the $\mathrm{Ti}^{+2}$ nanosize ions forming a coordination bond with the $\mathrm{C}=\mathrm{O}$ groups of the ester. As a result, the blend structure has taken on a complex configuration[31]. The presence of an interaction between blend and nanoparticles could explain the low intensities of the peaks in the range of $3100-2800 \mathrm{~cm}^{-1}$, with the position shifted to a lower wavenumber. Figure 1 demonstrates the structural changes in the polymer blend caused by doping with 
different concentrations of $\mathrm{TiO}_{2}$. The study of these spectra revealed a change in the height (intensity) and position of some IR absorbance peaks, suggesting the presence of nanoparticles within the main chain of the polymer blend (See Scheme 1).

\subsection{DSC study}

The thermal behavior of the $\mathrm{TiO}_{2}$ NPs doped PANI/PMMA was studied using DSC from room temperature to $500^{\circ} \mathrm{C}$, as shown in Fig. 3.

For pure blends and nanocomposites, the figure depicts two endothermic peaks. The glass transition temperature $\left(\mathrm{T}_{\mathrm{g}}\right)$ of the relaxation mechanism resulting from the micro-Brownian motion of the backbone of the main chain was observed at the first transition around $100-120{ }^{\circ} \mathrm{C}$ using thermograms [32]. The middle of the first endothermic peak during heating is used to measure the $T_{g}$. Molecules below $T_{g}$ do not have segmental motion, and certain parts of the molecules may not wiggle but only vibrate slightly. The molecules will begin to vibrate near $\mathrm{T}_{\mathrm{g}}$, and segmental motion increases. Conformational changes, or changes in molecular structure, are induced by thermal motion or the action of an external field without rupturing chemical bonds. We noticed a single $\mathrm{T}_{\mathrm{g}}$ of the two polymers at $115{ }^{\circ} \mathrm{C}$, indicating that the PANI/PMMA interaction is miscible[33]. The broad endothermic peak around $315-380{ }^{\circ} \mathrm{C}$ for pure blend and nanocomposite were assigned to the $\mathrm{T}_{\mathrm{m}}$, indicating the semicrystalline nature of the pure blend. The depth of peak at Tm indicates a decrease in the crystallinity degree of the pure blend (semicrystalline) after addition filler and an increase in the amorphous fraction, this is consistent with the results of $\mathrm{XRD}[34,35]$.

\section{4. Thermogravimetric (TGA)}

The thermogravimetric (TGA) results of $\mathrm{TiO}_{2}$ nanoparticles doped PANI/PMMA blend in nitrogen atmosphere from 30 to $500{ }^{\circ} \mathrm{C}$ are shown in Figure 4. TGA curves are all smooth, with decomposition behaviors that are almost identical. In all of the curves, there are three weight losses. There was no evidence of non-oxidative degradation in any of the three steps. The first stage weight loss occurred at temperatures below $150{ }^{\circ} \mathrm{C}$ due to evaporation of intra- and intermolecular moisture [36], while the second step weight loss occurred at temperatures between 200 and $300{ }^{\circ} \mathrm{C}$ due to the thermal decomposition

of gases and functional groups such as $\mathrm{CO}, \mathrm{C}=\mathrm{O}$, and $\mathrm{NH}_{2}$ on the polymer blend 
backbone [37]. The thermal decomposition of the polymer blend backbone occurred in the third stage of thermal decomposition at above $350{ }^{\circ} \mathrm{C}$, and this weight loss section was caused by the thermal decomposition of the polymer blend backbone. These findings revealed that nanocomposites are more thermally stable than pure PANI/PMMA, implying that more stable structures or groups were produced through the interactions of PANI/PMMA and $\mathrm{TiO}_{2}$ nanoparticles.

\section{4i. Determine the kinetic parameters:}

Different methods can be used to quantify the activation energy for the thermal decomposition of the current samples. The following section introduces two distinct calculation methods:

\section{4. i. Coats - Redfern's method}

Coats and Redfern present a method for measuring the thermal activation energy, which is shown in equation.

$$
\log \left[\frac{1-(1-\alpha)^{1-n}}{T^{2}}\right]=\log \frac{R}{\Delta E}\left[1-\frac{2 R T}{E}\right]-\frac{1}{2.303} \frac{E_{a}}{R T}
$$

Using this equation, we can calculate activation energies $\left(\mathrm{E}_{\mathrm{a}}\right)$ by plotting the dependence of $-\log \left[\frac{-\log (1-\alpha)}{T^{2}}\right]$ against $1000 / \mathrm{T}$ for each sample (not here). The degree of decomposition $(\alpha)$ is defined as [38]:

$$
\alpha=\frac{m_{i}-m_{t}}{m_{i}-m_{f}}
$$

where $m_{i}, m_{f}$, and $m_{t}$ are the sample's initial, final, and total mass at time $t$, respectively. From the slope of the plot, the activation energy (Ea) was determined as:

$$
E_{\mathrm{a}}=2.203 R \times \text { slope }
$$

With increasing $\mathrm{TiO}_{2}$ nanoparticle content, the estimated activation energy reduces gradually from 230 to $185 \mathrm{Kcal} / \mathrm{mol}$. This reduction in activation energy values suggests that $\mathrm{TiO}_{2}$ nanoparticles have a major effect on thermal properties due to defects formed through the interaction of polymer chains with $\mathrm{TiO}_{2}$ and the creation of certain bonds. 


\section{4. ii. Broido's method}

The activation energy associated with each stage of decomposition is determined by the Broido model using the following equation[39]:

$$
\ln \left[\ln \left(\frac{1}{Y}\right)\right]=\left(-\frac{E_{a}}{R}\right) \frac{1}{T}+C
$$

Broido showed the weight of the prepared sample $\left(\mathrm{w}_{\mathrm{t}}\right)$ to thermal analysis at time $(t)$ is related to the fraction of initial molecules not yet decomposed (Y) using the relation:

$$
Y=\frac{W_{t}-W_{\infty}}{W_{i}-W_{\infty}}
$$

where, $w_{\mathrm{t}}$ is the weight at any time $\mathrm{t} ; w_{\infty}$ is the weight at infinite time and $w_{i}$ is the initial weight. A plot of $\ln [\ln (1 / \mathrm{Y})]$ vs. 1/T gives an excellent approximation to a straight line. The activation energy is proportional to the slope[40]. With raising the $\mathrm{TiO}_{2}$ nanoparticles content, there was a slight variation in the measured values of the activation energy, which decreased from (220 to 180$) \mathrm{Kcal} / \mathrm{mol}$, indicating that the $\mathrm{TiO}_{2}$ nanoparticles may affect the polymer characteristics. The measured activation energies (Ea) of the specimens are presented in Table (1).

\section{5. Optical characteristics}

The transmittance spectra of PANI/PMMA and PANI/PMMA doped $\mathrm{TiO}_{2}$ nanocomposites films are displayed in Figure5. Due to the many lattice defects of $\mathrm{TiO}_{2}$, the transmittance becomes lower with the addition of $\mathrm{TiO}_{2} \mathrm{NPs}$, leading to the reduction in the transparency of the nanocomposites. The achievement of direct and indirect band gap was from the plots of $(\alpha h v)^{2}$ and $(\alpha h v)^{1 / 2}$ versus $h v$ at $R T$, which allows us to obtain the values of $E g$ through extrapolating the linear part of $(\alpha h v)^{2}$ to zero as displayed in Fig. 6 (a,b). The $E_{g}$ (direct) values were about $5.04 \mathrm{eV}, 4.47 \mathrm{eV}$, and $5.31 \mathrm{eV}$ for PANI/PMMA, (1.5 and 2.3) wt $\%$ of $\mathrm{TiO}_{2}$ doped PANI/PMMA, respectively. The polymer disorder grade variations resulting from the changes of polymer frame PANI/PMMA and $\mathrm{TiO}_{2}$ NPs cause the reduction in the polymer blend's optical bandgap energy. Thus, the localized states in the band gap are stimulated by these defects and are the cause for decreasing the band gap energy of the polymer[41]. It can be observed that the energy gap decreased with the raising rate of $\mathrm{TiO}_{2} \mathrm{NPs}$ as a result of the increase of 
the interaction of the carriers taking place in valence and conduction bands resulting in the change in the valence and the conduction band and decreasing the band gap. On the other hand, the reduction occurring in the optical gap is an indicator of the creation of charge transfer complexes (CTCs) as trap levels of HOMO with the polymer blend's LUMO bands [42]. This, in turn, leads to the improvement of the decreased energy transitions proving the desirable miscibility of $\mathrm{TiO}_{2}$ NPs with the PANI/PMMA chains. The observed improvement also emphasizes the results of the study of XRD and DSC. Previous reports have shown the same behavior for PVA and PVA/ PVP doped $\mathrm{TiO}_{2}$, respectively[43]. Fig. 7 displays the distributions of refractive index of $\mathrm{TiO}_{2}$ doped PANI/PMMA nanocomposites films. The index of refraction values became higher upon adding $\mathrm{TiO}_{2}$ NPs. Previous reports have shown the same behavior for $\mathrm{PVA} / \mathrm{TiO}_{2}$ and PVA/ZnO nanocomposites[44]. This raise in the values makes them useful as antireflective coatings. The raise in the refractive index and the reduction in the optical band gap evidence the raise in the disorder nature upon raising $\mathrm{TiO}_{2}$ concentration as it is in a good agreement with the XRD. Moreover, Fig. 8 presents the electric susceptibility value to be higher than 1 and demonstrates in its inset that the electric susceptibility $(\chi \mathrm{c})$ to become higher with the addition of $\mathrm{TiO}_{2}$, which evidence the possible polarization of the material as the incident light becomes denser.

$\mathrm{PANI} / \mathrm{PMMA} / \mathrm{TiO}_{2}$ nanocomposites films and the optical absorption coefficients versus the pure blend photon energy are displayed in Figure 9. It should be noticed that the optical absorption coefficients of pure blend became higher upon raising $\mathrm{TiO}_{2} \mathrm{NPs}$ contents which is ascribed to boost number of charge carriers. The absorption edge venue $\left(\mathrm{E}_{\mathrm{d}}\right)$ was identified via the extrapolation of the $\alpha$ linear part with the hv curves compared to the zero absorption value [36]. The decreasing of the absorption edge notably occurs with the addition of the nanoparticles of $\mathrm{TiO}_{2}$ to the polymer matrix as displayed in Table1. Another reason for the shift in the polymer blend absorption edge is explained in terms of the changes in the structure of polymer films. These changes are proved by XRD and are caused by the interactions occurring in and between the polymer chains molecular with $\mathrm{TiO}_{2}$ NPs. 
In addition, it should also be noticed that the presence of the absorption coefficient $\alpha(v)$ near the band edge is shown to be dependent exponentially on energy of photon (hv) following the mathematical relations provided by Urbach [45]:

$$
\alpha(\mathrm{v})=\alpha_{o} \mathrm{e}^{(\mathrm{hu} / \mathrm{Ee})}
$$

in which $\alpha_{o}$ is constant, and $E_{e}$ stands for the tail of the band (Urbach tail), that stands for the width of localized state. The logarithm of absorption coefficient $(\alpha)$ plots are shown in the Urbach plot as a photon energy hv function as displayed in Fig.10. Table 1 shows a list of the samples band tail $\left(\mathrm{E}_{\mathrm{e}}\right)$ values determined by the curves' slopes reciprocal of the linear portion. The values of $\mathrm{E}_{\mathrm{e}}$ noticeably raise from $0.79096 \mathrm{eV}$ of a pure blend film to $1.38579 \mathrm{eV}$ for PANI/PMMA/1.5\% $\mathrm{TiO}_{2}$ film. Consequently, the change in the values of $E_{e}$ inversely with values of $E_{g}$ can be understood as caused by the increasing disorder of the polymer matrix. This raising in the tail of the band is the result of the influence of interaction occurring within the chains of $\mathrm{TiO}_{2} \mathrm{NPs}$ polymer blend. The redistribution of the states from band to tail is caused by the $\mathrm{TiO}_{2} \mathrm{NPs}$, which consequently allows tail-totail transitions to take place in a great number. The following relation is used for determining the atoms of carbon number for each cluster $(\mathrm{N})$ of the optical energy band gap Eg [46]:

$$
E_{g}=34.4 / \sqrt{ } N
$$

Table 1 shows the $\mathrm{N}$ values of pure blend film, and $\mathrm{PANI} / \mathrm{PMMA} / \mathrm{TiO}_{2}$ nanocomposites films. It should be noticed that, the $\mathrm{N}$ value of the pure blend film is about 46.5 and rises to 60.1 in PANI/PMMA/1.5\% $\mathrm{TiO}_{2}$ nanocomposites film as a result of the monomer units conjugation of PANI/PMMA matrix posts encompassing the $\mathrm{TiO}_{2}$ nanoparticles.

The reflectance (R) of PANI/PMMA and nanocomposites films has been investigated as a function of wavelength at room temperature, as shown in Fig. 11. The boost of the wavelength causes the reflectance to reduce and become constant at increased wavelengths of all films. This can lead to the conclusion that the reflectance (R) is responsible for local fluctuations charged particles cause to be lower with the doping of $\mathrm{TiO}_{2}$ nanoparticles in polymer blend. The decrease in the reflectance presents a raise in 
the incident light scattering indicating the increase in the level of disorder in the composite films resulting from the structural change in the polymer. Meanwhile, the values variation of the reflectance indicate the formation of $\mathrm{TiO}_{2} \mathrm{NPs}$ as an essential factor in the modification of the polymer matrix electronic structure [47].

\section{6. Optical dielectric parameters}

The optical dielectric parameters rely on the structural band of the material and are relevant to the energy of states density inside the optical band gap of the samples. The equation below shows calculated value of the optical dielectric constant $\left(\varepsilon^{\prime}\right)$ and the optical dielectric loss $\left(\varepsilon^{\prime \prime}\right)$ :

$$
\begin{aligned}
& \varepsilon^{\prime}=n^{2}-k^{2} \\
& \varepsilon^{\prime \prime}=2 n k
\end{aligned}
$$

For the pure blend and nanocomposites samples, Figure 12(a,b) depicts the relationship between $\varepsilon^{\prime}$ and $\varepsilon^{\prime \prime}$ as a function of incident photon energy. The $\varepsilon^{\prime}$ and $\varepsilon^{\prime \prime}$ relation becomes stronger with raising the $\mathrm{TiO}_{2}$ nanoparticles content in the polymer matrix. Fig. 12 demonstrates the reduction of the dielectric constant and dielectric loss after increasing the incident photon energy of light to $2.5 \mathrm{eV}$, and the raising in the absorption edge region followed by this reduction due to the polarization[48]. Obviously, the formation defects observed by the reaction of the charge transfer of the pure polymer blend chain with the $\mathrm{TiO}_{2}$ NPs dopant are responsible for this raise in dielectric and loss dielectric constant with the addition of $\mathrm{TiO}_{2}$ NPs into pure polymer blend and nanocomposites films.

The motion of free carriers caused by the incident electromagnetic waves is responsible for the optical conductivity $\left(\sigma_{\mathrm{opt}}\right)$. The values of $n$ and $\alpha$ are determined and presented in the equation below [49],

$$
\sigma_{o p t}=n \alpha C / 4 \pi
$$


In which $C$ refers to light speed in vacuum. The optical conductivity along with the incident light photon energy of the pure blend and nanocomposites films Figure13. It should be noticed that the optical conductivity also becomes higher with the higher concentration of $\mathrm{TiO}_{2}$ nanoparticles. The charge transfer formation of the molecules of the blend with the $\mathrm{TiO}_{2}$ nanoparticles has a relation to such behavior [50]. The polymer chains were broken by the $\mathrm{TiO}_{2}$ nanoparticles, which could lead to the formation of hydrogen bonding of $\mathrm{TiO}_{2}$ nanoparticles with the blend molecules. In addition, as the density of the localized states in the structural band become higher, the nanoparticles become higher simultaneously, thus causing the increase in the optical conductivity along with the absorption coefficient [51]. It should be noticed that there was a strong increase in the optical conductivity in the absorption edge region in relation to the strong increase of free charge carriers resulting from the sufficient energy of the incident photon which surmounted the band gap of the polymer film[52].

\section{Conclusion}

In this study, a blend doped with $\mathrm{TiO}_{2}$ was synthesized and $\mathrm{TiO}_{2}$ nanoparticles were analyzed via an XRD. The linear and nonlinear optical characteristics of these samples were investigated, and their internal structural changes were studied with the use of FTIR. The optical band and the structural characteristics of the synthesized nanocomposite thin films were determined through the analysis of the absorbance, transmittance, and reflectance spectra. The analysis was applied on the optical properties of the samples including the optical constants ( $\mathrm{n}$ and $\mathrm{k}$ ), optoelectronic, dispersion, bandgap energy as well as their absorbance, transmittance, and reflectance spectra. The value of blend thin film transmittance in the visible region was about $92 \%$. This value was noticeably low with the introduction of $\mathrm{TiO}_{2}$ NPs into blend of the thin films, which, consequently, indicates the strong effect of this reduction on the relevant optical parameters. The $\mathrm{E}_{\mathrm{g}}$ value (direct and indirect) of the blend doped with various $\mathrm{TiO}_{2}$ concentrations and its noticed low value upon raising $\mathrm{TiO}_{2}$ content were also determined. This reduction was caused by the high of mobile charge carriers number as well as the increase in blend's amorphous nature of the polymer. Such values are in a significant consistence with the bandgap values determined by the use of the Tauc technique. 
Furthermore, the calculated value of the energy of Urbach of blend thin film was found to be significantly high with the introduction of $\mathrm{TiO}_{2} \mathrm{NPs}$ into blend thin films. This high energy of Urbach of PANI/PMMA/TiO 2 thin films reflects the strong disorder in the thin films. The results of the analysis of the absorbance, transmittance, and reflectance spectra assisted in determining the optical characteristics including the optical constants ( $\mathrm{n}$ and $\mathrm{k}$ ), optoelectronic, dispersion, bandgap energy, and the structural characteristics of the band of the synthesized nanocomposite thin films. The value of the blend transmittance of thin film was $92 \%$ approximately, in the visible region. It was noticed that the transmittance value of the thin films became lower with the introduction of $\mathrm{TiO}_{2} \mathrm{NPs}$ into blend thin films. Therefore, this reduction has a significant effect on the relevant optical parameters. Moreover, the values which were found for the optoelectronic, refractive index and third order susceptibility indicated the significant effect of the doping blend with $1.5 \mathrm{wt} . \%$ of $\mathrm{TiO}_{2}$. Thus, such results present a great evidence of the potential use of $\mathrm{TiO}_{2}$-doped blend in optical applications.

\section{Conflicts of interest:}

The authors declare that they have no conflict of interest. 


\section{References}

[1] P. Dhatarwal, R.J. Sengwa, S. Choudhary, Effectively improved ionic conductivity of montmorillonite clay nanoplatelets incorporated nanocomposite solid polymer electrolytes for lithium ion-conducting devices, SN Appl. Sci. 1 (2019) 112.

[2] S. Choudhary, R.J. Sengwa, Effects of different inorganic nanoparticles on the structural, dielectric and ion transportation properties of polymers blend based nanocomposite solid polymer electrolytes, Electrochim. Acta. $247 \quad$ (2017) 924-941. https://doi.org/10.1016/J.ELECTACTA.2017.07.051.

[3] M.M. Abutalib, A. Rajeh, Influence of $\mathrm{ZnO} / \mathrm{Ag}$ nanoparticles doping on the structural, thermal, optical and electrical properties of PAM/PEO composite, Phys. B Condens. Matter. 578 (2020) 411796. https://doi.org/10.1016/J.PHYSB.2019.411796.

[4] A. Rajeh, H.M. Ragab, M.M. Abutalib, Co doped ZnO reinforced PEMA/PMMA composite: Structural, thermal, dielectric and electrical properties for electrochemical $\begin{array}{llllll}\text { applications, } & \text { J. } & \text { Mol. } & \text { Struct. } & 1217 & \text { (2020) }\end{array}$ https://doi.org/10.1016/J.MOLSTRUC.2020.128447.

[5] A.M. Hezma, A. Rajeh, M.A. Mannaa, An insight into the effect of zinc oxide nanoparticles on the structural, thermal, mechanical properties and antimicrobial activity of Cs/PVA composite, Colloids Surfaces A Physicochem. Eng. Asp. 581 (2019) 123821. https://doi.org/10.1016/J.COLSURFA.2019.123821.

[6] C. M. Magdalane, et al. "Photocatalytic decomposition effect of erbium doped cerium oxide nanostructures driven by visible light irradiation: Investigation of cytotoxicity, antibacterial growth inhibition using catalyst.” Journal of Photochemistry and Pho, (n.d.).

[7] L. N. Ismail, et al. "Electrical characterization of metal insulator semiconductor using $\mathrm{ZnO}$ low deposition temperature as semiconductor layer." Advanced Materials Research. 832 (2014) 270-275.

[8] S. S. Nafee, Taymour A. Hamdalla, and A. A. A. Darwish. "Studies of the morphology and optical properties of nano erbium oxide embedded in PMMA matrix." Optics \& Laser Technology 129 (2020) 106282.

[9] T. A. Hamdalla, Taha A. Hanafy, and Seleim M. Seleim. "Effect of rare earth elements on the structural and optical properties of PMMA for possible uses in polymer optical communications." Phase Transitions 92 (2019) 603-613.

[10] Marangoni, Rafael, Alexandre Mikowski, and Fernando Wypych. "Effect of adsorbed/intercalated anionic dyes into the mechanical properties of PVA: Layered zinc hydroxide nitrate nanocomposites." Journal of colloid and interface science 351 (2010) 384-391.

[11] S. Soumya, et al. "Enhanced near-infrared reflectance and functional characteristics of 
Al-doped ZnO nano-pigments embedded PMMA coatings.” Solar Energy Materials and Solar Cells 143 (2015) 335-346.

[12] T. M. George, et al. "Bright red luminescence and triboluminescence from PMMA-doped polymer film materials supported by Eu3+-triphenylphosphine based $\beta$-diketonate and 4, 5-bis (diphenylphosphino)-9, 9-dimethylxanthene oxide." Journal of Photochemistry and Photobiology A: Chemistry 317 (2016): 88-99

[13] Kar, Pradip, Narayan C. Pradhan, and Basudam Adhikari. "Application of sulfuric acid doped poly (m-aminophenol) as aliphatic alcohol vapor sensor material." Sensors and Actuators B: Chemical 140 (2009) 525-531.

[14] Asyraf, Mohammad, et al. "Recent development of nanomaterial-doped conductive polymers." Jom 69 (2017) 2515-2523.

[15] Z. Li, and Yanwei Wang. "Characterization of polyaniline/Ag nanocomposites using $\mathrm{H} 2 \mathrm{O} 2$ and ultrasound radiation for enhancing rate." Polymer composites 31 (2010) 16621668.

[16] M. S. Katore, S. S. Yawale, and S. P. Yawale. "Photovoltaic study of chemically engineered nano-titanium oxide loaded polyaniline matrix of architecture ITO/titanium oxide-polyaniline/aluminum." Synthetic Metals 209 (2015) 577-582.

[17] G. Sahu, et al. "Dielectric relaxation behavior of silver nanoparticles and graphene oxide embedded poly (vinyl alcohol) nanocomposite film: An effect of ionic liquid and temperature.” Polymers 12 (2020) 374.

[18] Y. Xue, et al. "Nanostructured conducting polymers and their composites: synthesis methodologies, morphologies and applications." Journal of Materials Chemistry. C 8 (2020)10136-10159.

[19] K.M. Ismayil, A. Varghese, R. Antony, Silver-doped polyaniline-polyvinyl chloride nanocomposite films for photocatalytic and antibacterial applications. J. Elastomers Plast. 52 (2020) 103-116.

[20] M.M. Abutalib, A. Rajeh, Influence of MWCNTs/Li-doped TiO2 nanoparticles on the structural, thermal, electrical and mechanical properties of poly (ethylene oxide)/poly (methylmethacrylate) composite, J. Organomet. Chem. $918 \quad$ (2020) 121309. https://doi.org/10.1016/J.JORGANCHEM.2020.121309.

[21] M.M. Abutalib, A. Rajeh, Preparation and characterization of polyaniline/sodium alginatedoped $\mathrm{TiO} 2$ nanoparticles with promising mechanical and electrical properties and antimicrobial activity for food packaging applications, J. Mater. Sci. Mater. Electron. 31 (2020) 9430-9442. https://doi.org/10.1007/s10854-020-03483-8.

[22] M. A. Behnajady, et al. "Sol-gel low-temperature synthesis of stable anatase-type TiO2 nanoparticles under different conditions and its photocatalytic activity." Photochemistry and Photobiology 87 (2011) 1002-1008. 
[23] A. D. Paola, et al. "Highly active photocatalytic $\mathrm{TiO} 2$ powders obtained by thermohydrolysis of TiCl4 in water." The Journal of Physical Chemistry C. 113 (2009) 15166-15174.

[24] M. Kumar, and Dinesh Kumar. "The deposition of nanocrystalline TiO2 thin film on silicon using Sol-Gel technique and its characterization." Microelectronic engineering 87 (2010) 447-450.

[25] M. M. Abutalib, and A. Rajeh. "Enhanced structural, electrical, mechanical properties and antibacterial activity of $\mathrm{Cs} / \mathrm{PEO}$ doped mixed nanoparticles $(\mathrm{Ag} / \mathrm{TiO} 2)$ for food packaging applications.” Polymer Testing 93 (2021) 107013.

[26] M. T. Ramesan, and T. Sampreeth. "In situ synthesis of polyaniline/Sm-doped TiO 2 nanocomposites: evaluation of structural, morphological, conductivity studies and gas sensing applications.” Journal of Materials Science: Materials in Electronics 29 (2018).

[27] M.M. Abutalib, A. Rajeh, Influence of $\mathrm{Fe} 3 \mathrm{O} 4$ nanoparticles on the optical, magnetic and electrical properties of PMMA/PEO composites: Combined FT-IR/DFT for electrochemical applications, J. Organomet. Chem. $920 \quad$ (2020) 121348. https://doi.org/10.1016/J.JORGANCHEM.2020.121348.

[28] P. Manivel, et al. "Rheological behavior and electrical properties of polypyrrole/thermally reduced graphene oxide nanocomposite." Colloids and Surfaces A: Physicochemical and Engineering Aspects, 441 (2014) 614-622.

[29] B. K. Bahuleyan, C. Induja, and M. T. Ramesan. "Influence of titanium dioxide nanoparticles on the structural, thermal, electrical properties, and gas sensing behavior of polyaniline/phenothiazine blend nanocomposites." Polymer Composites 40 (2019) 4416-4.

[30] M.M. Abutalib, Insights into the structural, optical, thermal, dielectric, and electrical properties of PMMA/PANI loaded with graphene oxide nanoparticles, Phys. B Condens. Matter. 552 (2019) 19-29. https://doi.org/10.1016/J.PHYSB.2018.09.034.

[31] S. Soumya, et al. "Enhanced near-infrared reflectance and functional characteristics of Aldoped $\mathrm{ZnO}$ nano-pigments embedded PMMA coatings." Solar Energy Materials and Solar Cells. 143 (2015) 335-346.

[32] A.M. Hezma, I.S. Elashmawi, E.M. Abdelrazek, A. Rajeh, M. Kamal, Enhancement of the thermal and mechanical properties of polyurethane/polyvinyl chloride blend by loading single walled carbon nanotubes, Prog. Nat. Sci. Mater. Int. 27 (2017). https://doi.org/10.1016/j.pnsc.2017.06.001.

[33] A.M. Hezma, I.S. Elashmawi, A. Rajeh, M. Kamal, Change Spectroscopic, thermal and mechanical studies of PU/PVC blends, Phys. B Condens. Matter. 495 (2016) 4-10. https://doi.org/10.1016/j.physb.2016.04.043.

[34] M. Hema, S. Selvasekarapandian, D. Arunkumar, A. Sakunthala, H. Nithya, FTIR, XRD and ac impedance spectroscopic study on PVA based polymer electrolyte doped with 
NH4X (X=Cl, Br, I), J. Non. Cryst. Solids. 355 (2009) 84-90.

[35] M.K. El-Mansy, E.M. Sheha, K.R. Patel, G.D. Sharma, Characterization of PVA/CuI polymer composites as electron donor for photovoltaic application, Opt. - Int. J. Light Electron Opt. 124 (2013) 1624-1631. https://doi.org/10.1016/j.ijleo.2012.05.009.

[36] A.M. Al-Sabagh, N.G. Kandile, R.A. El-Ghazawy, M.R. Noor El-Din, E.A. El-sharaky, Synthesis and characterization of high molecular weight hydrophobically modified polyacrylamide nanolatexes using novel nonionic polymerizable surfactants, Egypt. J. Pet. 22 (2013) 531-538. https://doi.org/10.1016/j.ejpe.2013.11.007.

[37] C.K. Choo, X.Y. Kong, T.L. Goh, G.C. Ngoh, B.A. Horri, B. Salamatinia, Chitosan/halloysite beads fabricated by ultrasonic-assisted extrusion-dripping and a case study application for copper ion removal, Carbohydr. Polym. 138 (2016) 16-26. https://doi.org/10.1016/j.carbpol.2015.11.060.

[38] A.M. Hezma, I.S. Elashmawi, A. Rajeh, M. Kamal, Change Spectroscopic, thermal and mechanical studies of PU/PVC blends, Phys. B Condens. Matter. 495 (2016) 4-10. https://doi.org/10.1016/j.physb.2016.04.043.

[39] A. Broido, A simple, sensitive graphical method of treating thermogravimetric analysis data, J. Polym. Sci. Part A-2. 7 (1969) 1761-1773. https://doi.org/10.1002/pol.1969.160071012.

[40] A.M. Hezma, I.S. Elashmawi, A. Rajeh, M. Kamal, Spectroscopic and thermal properties of PU/PVC doped with multi walled carbon nanotube, Der Pharma Chem. 8 (2016) 201208. http://derpharmachemica.com/archive.html.

[41] T. Soliman, A. Abouhaswa, Synthesis and structural of $\mathrm{Cd} 0.5 \mathrm{Zn} 0.5 \mathrm{~F} 2 \mathrm{O} 4$ nanoparticles and its influence on the structure and optical properties of polyvinyl alcohol films. J. Mater. Sci.: Mater. Electron. 31 (2020) 9666-74.

[42] O.G. Abdullah, S.B. Aziz, M.A. Rasheed, Structural and optical characterization of PVA: KMnO4 based solid polymer electrolyte. Results Phys. 6 (2016) 1103-1108.

[43] K. Rajesh, et al. "Structural, optical, mechanical and dielectric properties of titanium dioxide doped PVA/PVP nanocomposite.” Journal of Polymer Research 26 (2019) 1-10.

[44] N. J. Mohammed, Zahraa S. Rasheed, and Ashraf S. Hassan. "Improvement optical properties of pva/tio2 and pva/zno nanocomposites." Al-Mustansiriyah Journal of Science 29 (2019) 118-123.

[45] F.H. Abd El-kader, N. a. Hakeem, I.S. Elashmawi, a. M. Ismail, Enhancement of structural and thermal properties of PEO/PVA blend embedded with $\mathrm{TiO} 2$ nanoparticles, Indian J. Phys. 87 (2013) 983-990. https://doi.org/10.1007/s12648-013-0333-1.

[46] A.M. Abdel Reheem, A. Atta, T.A. Afify, Optical and electrical properties of argon ion beam irradiated PVA/Ag nanocomposites. Surf. Rev. Lett. 24(2017) 1750038. 
[47] M. Ghanipour, D. Dorranian, Effect of Ag-nanoparticles doped in polyvinyl alcohol on the structural and optical properties of PVA films. J. Nanomater. (2013). https://doi.org/ $10.1155 / 2013 / 897043$.

[48] S.B. Aziz, H.M. Ahmed, A.M. Hussein, A.B. Fathulla, R.M. Wsw, R.T. Hussein, Tuning the absorption of ultraviolet spectra and optical parameters of aluminum doped PVA based solid polymer composites. J. Mater. Sci. Mater. Electron. 26 (2015) 8022-8028.

[49] T.A. Taha, A. Saleh, Dynamic mechanical and optical characterization of PVC/fGO polymer nanocomposites. Applied Physics A 124 (2018) 1-12

[50] T. S. Soliman, A. S. Abouhaswa. "Synthesis and structural of Cd 0.5 Zn 0.5 F 2 O 4 nanoparticles and its influence on the structure and optical properties of polyvinyl alcohol films." Journal of Materials Science: Materials in Electronics 31 (2020) 9666-9.

[51] H. Ahmed, H.M. Abduljalil, A. Hashim, Structural, optical and electronic properties of novel (PVA-MgO)/SiC nanocomposites films for humidity sensors. Trans. Electr. Electron. Mater. 20 (2019)218-232 .

[52] M.B. Mohamed, M.H. Abdel-Kader, Effect of excess oxygen content within different nano-oxide additives on the structural and optical properties of PVA/PEG blend. Appl. Phys. A Mater. Sci. Process. 125 (2019) 1-11 . 
Figures
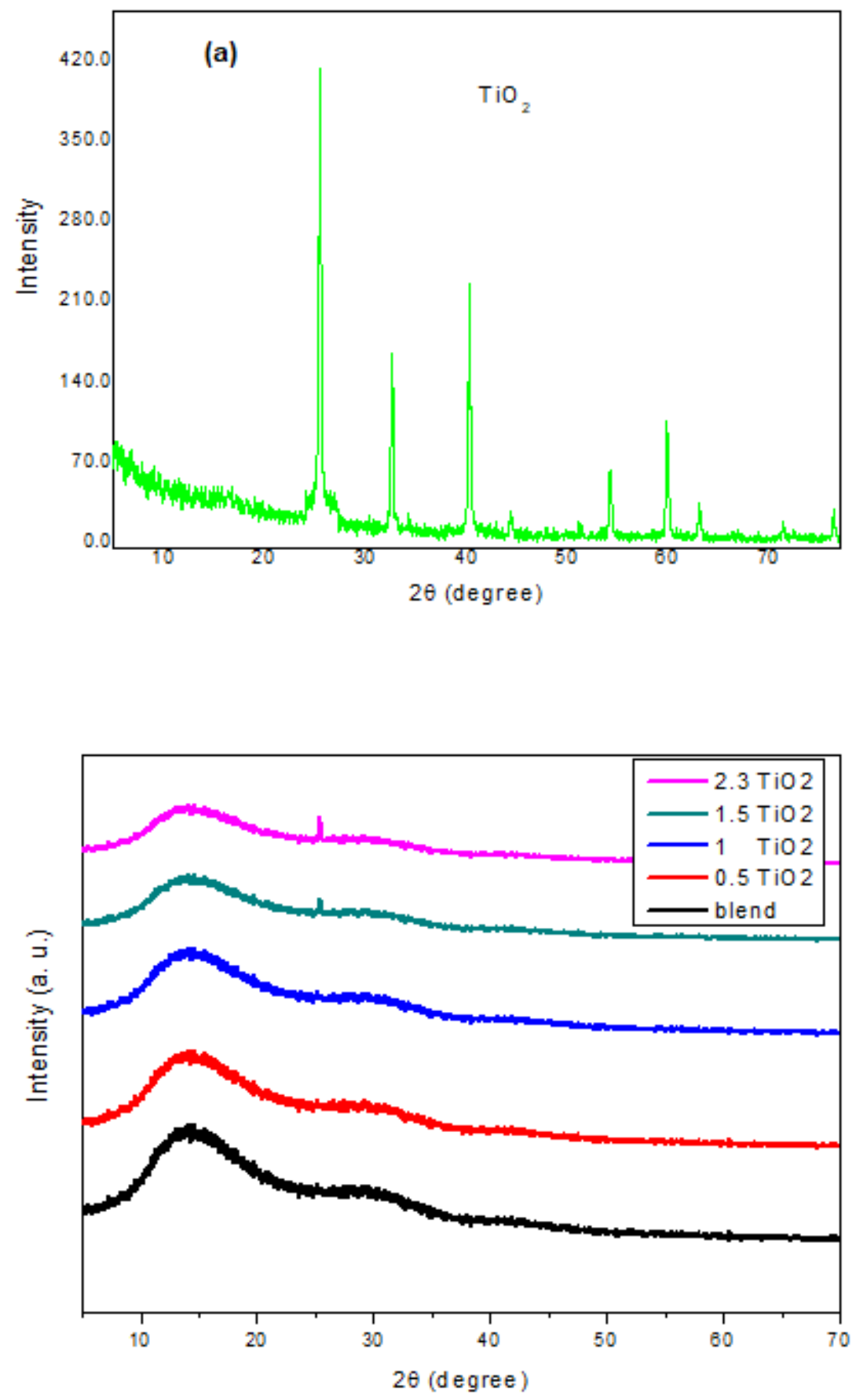

Figure 1

XRD patterns of (a) pristine of TiO2 NPs and (b) nanocomposites films. 


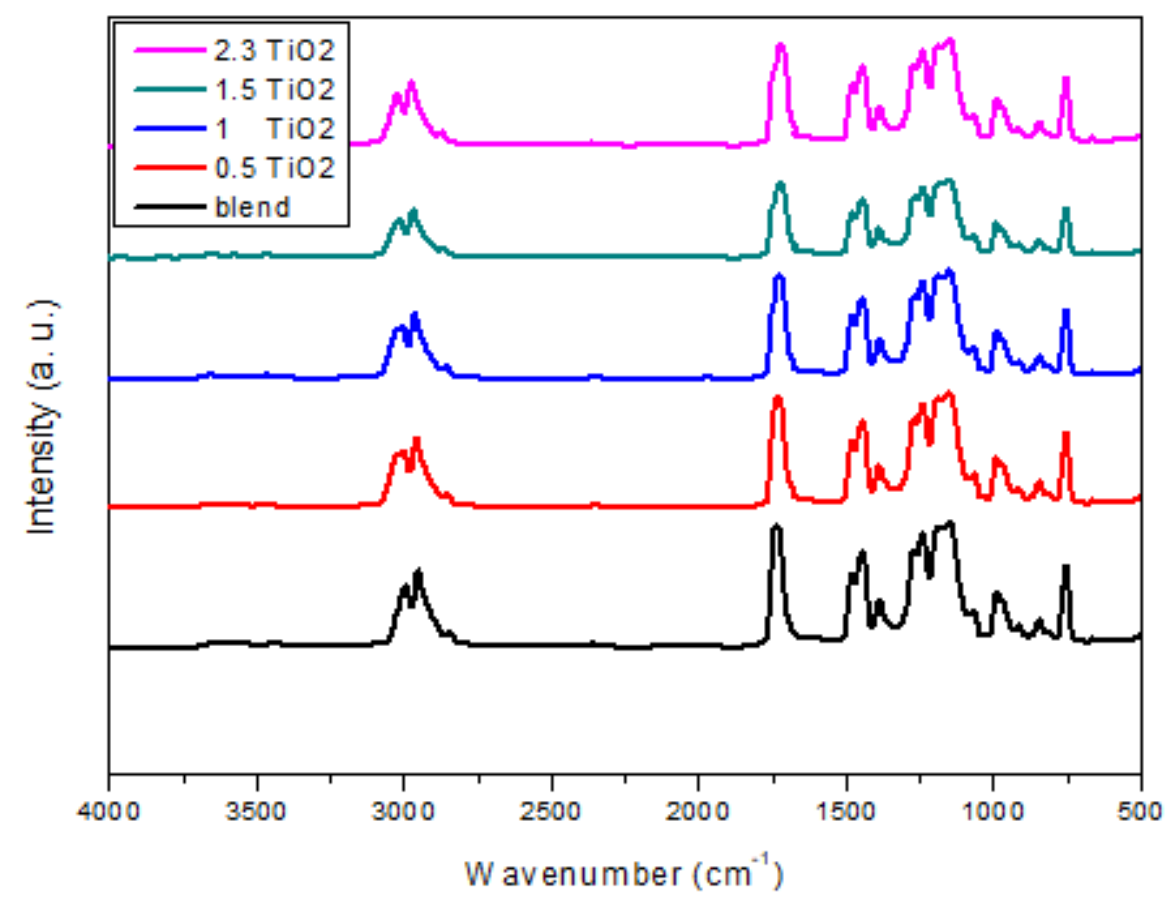

Figure 2

The FTIR spectra pure PANI/PMMA and nanocomposites films.

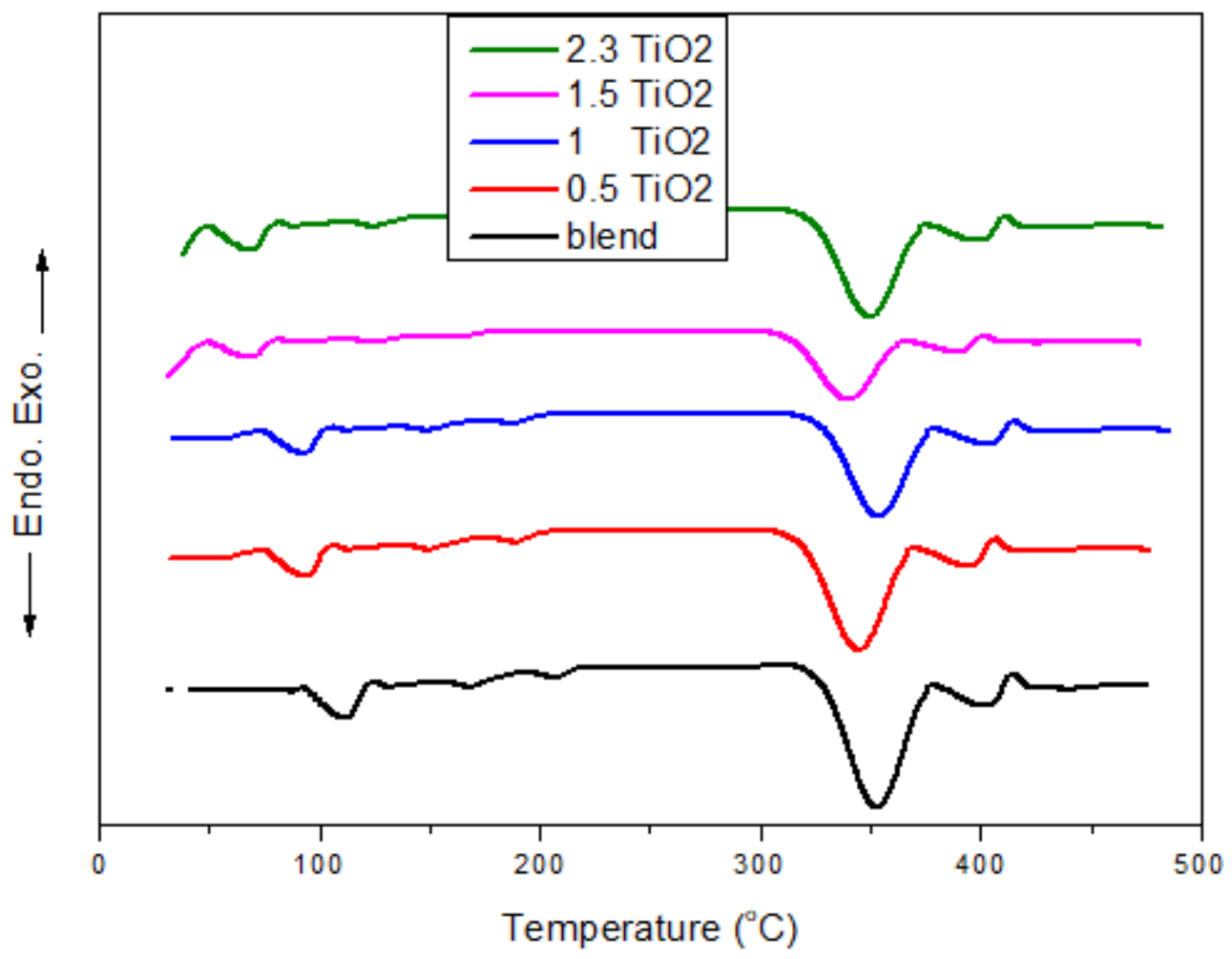

Figure 3 
DSC profiles of PANI/PMMA blend with different contents of TiO2 nanoparticles

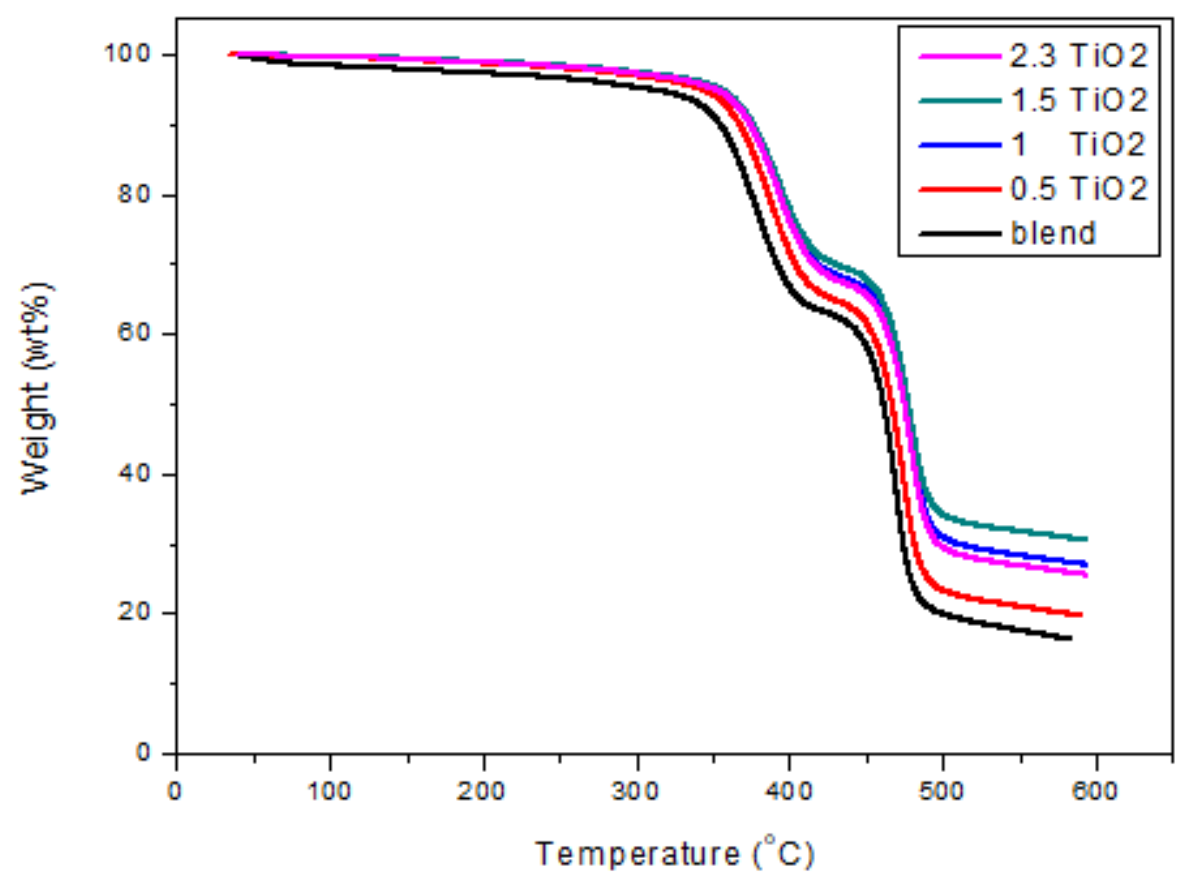

Figure 4

The TGA thermograms of pure PANI/PMMA, and blend incorporated with TiO2 NPs nanocomposites.

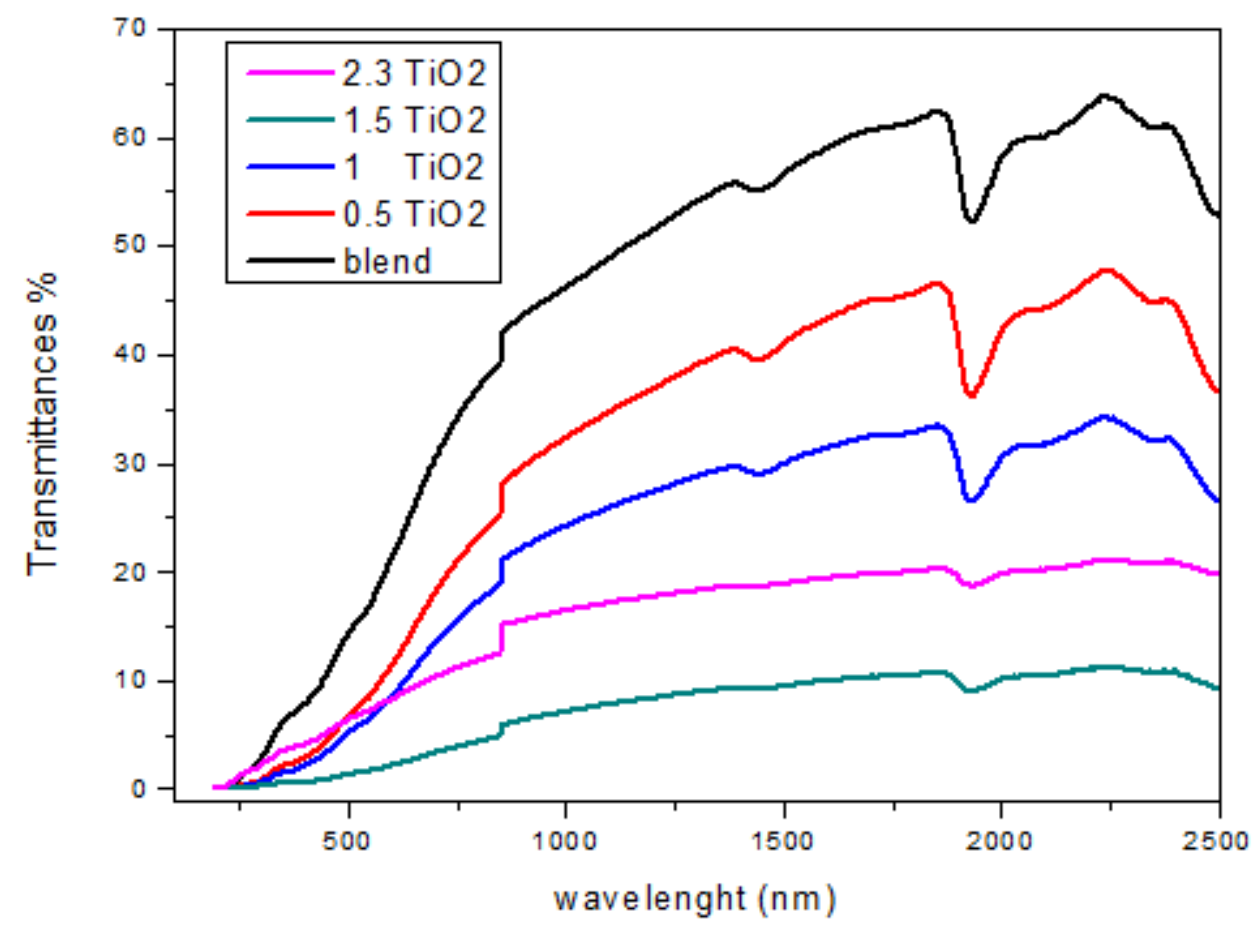

Figure 5 
Transmittance spectra of pure PANI/PMMA, and blend incorporated with TiO2 NPs nanocomposites.
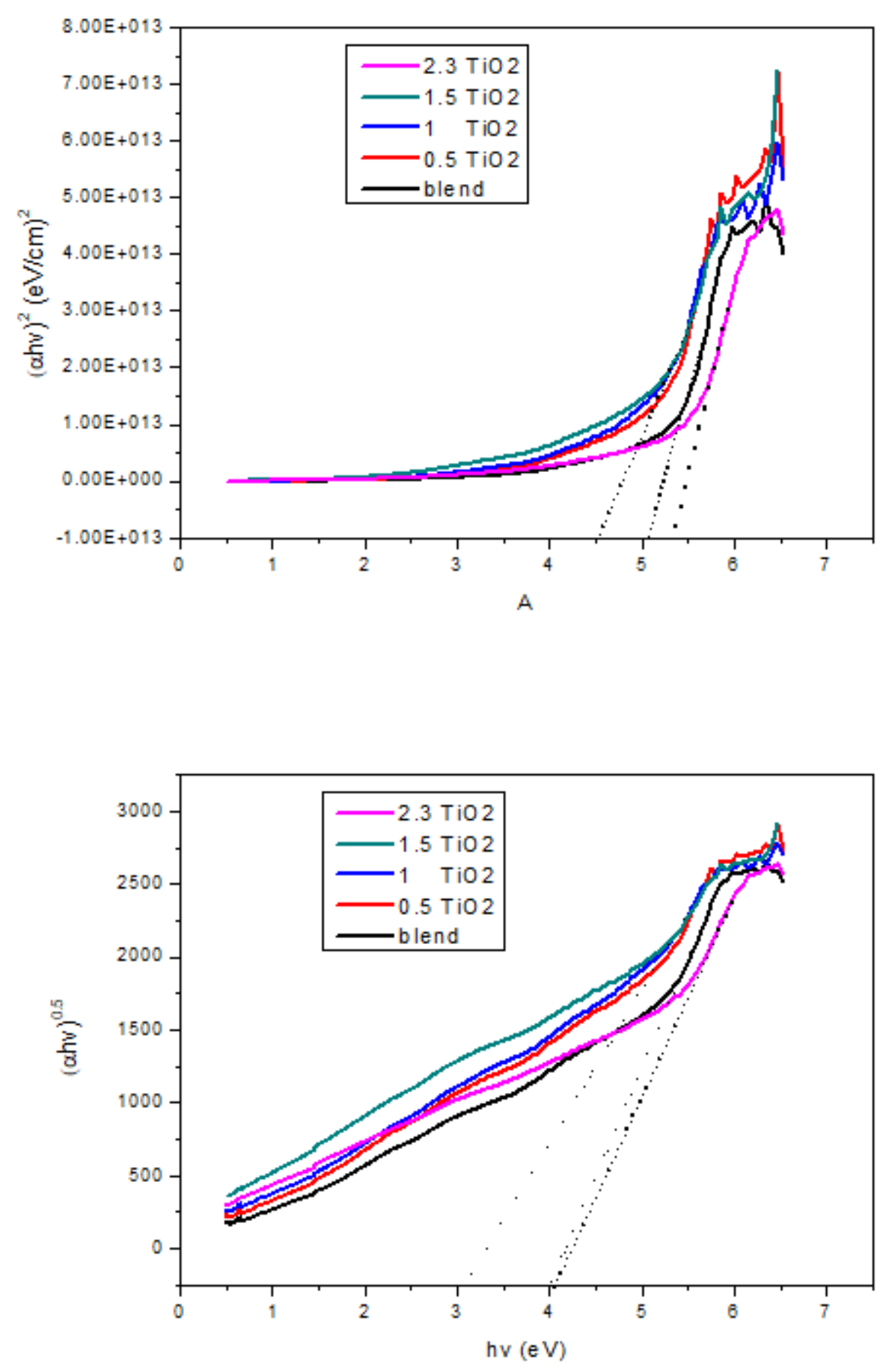

Figure 6

Plot of (a) (ahu)2 and (b) (ahu)1/2 vs photon energy for pure PANI/PMMA and nanocomposites. 


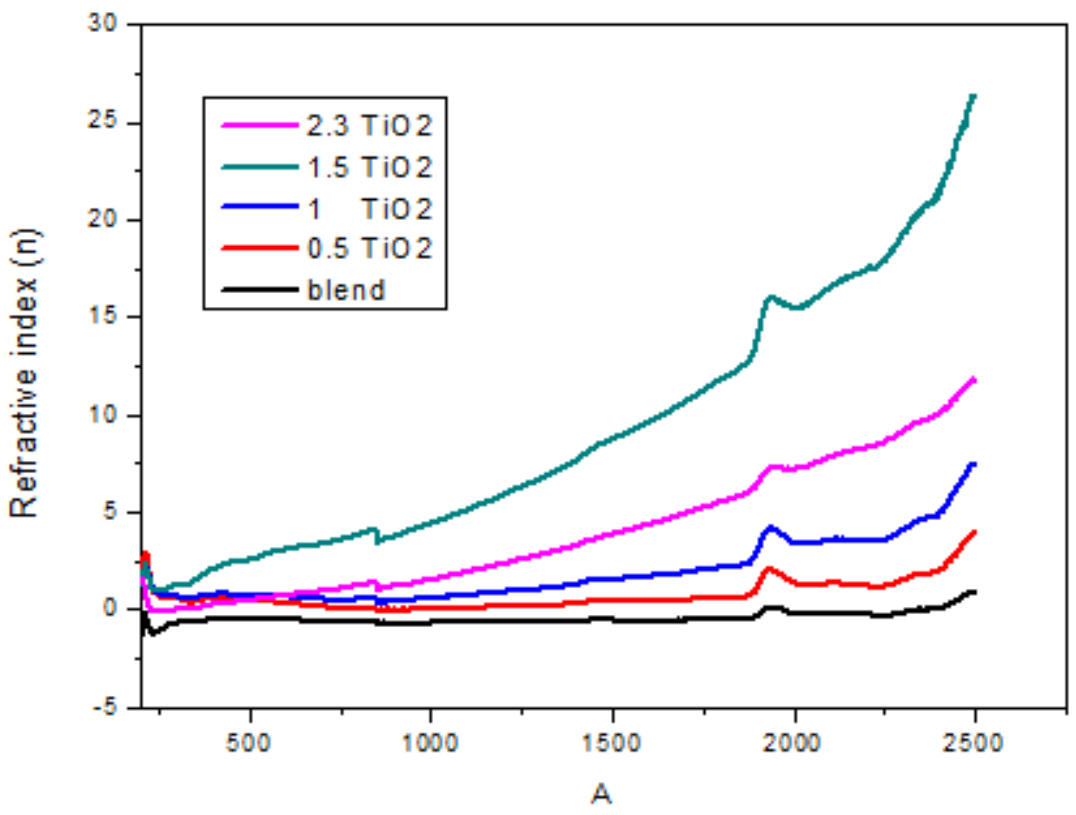

Figure 7

Refractive index (n) of the pure PANI/PMMA and nanocomposites films.

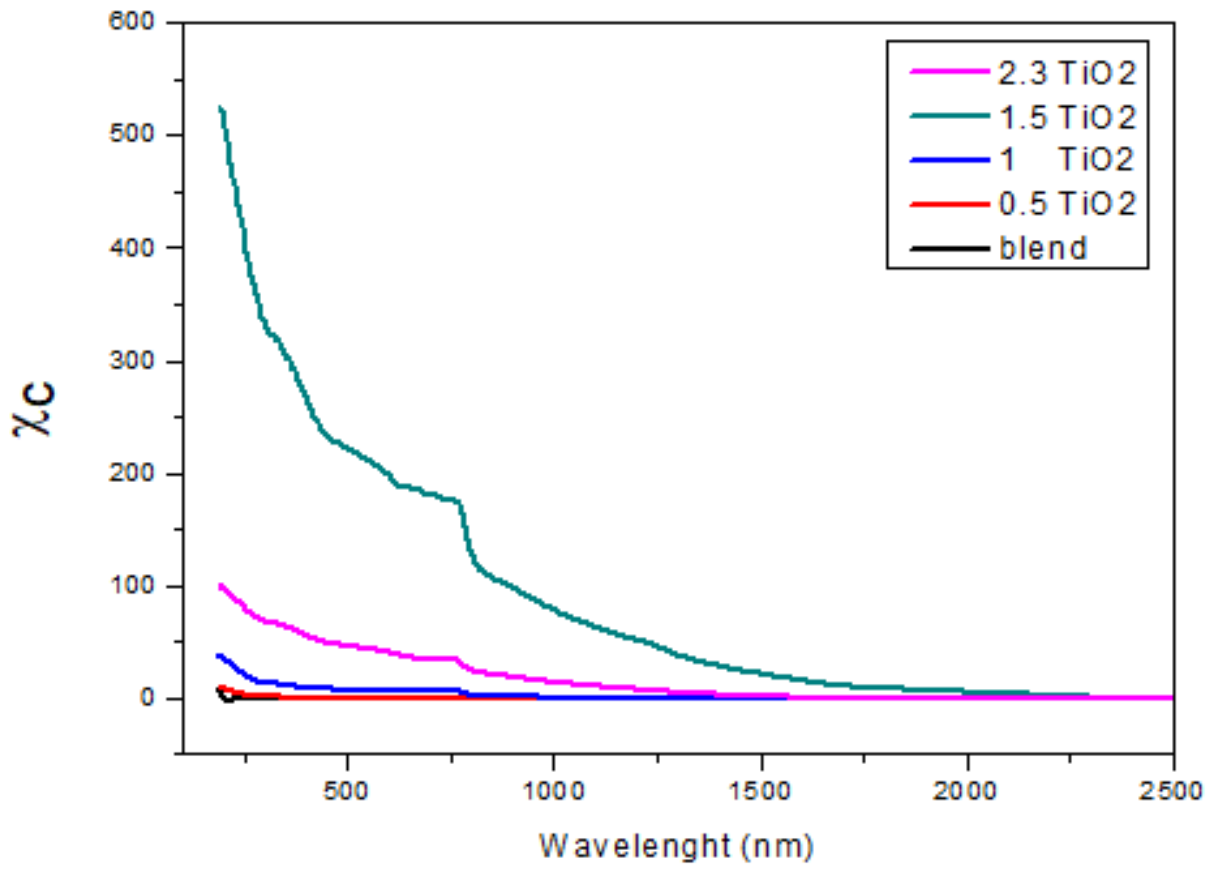

Figure 8

shows the electric susceptibility $(\chi c)$ for pure PANI/PMMA and nanocomposites films. 


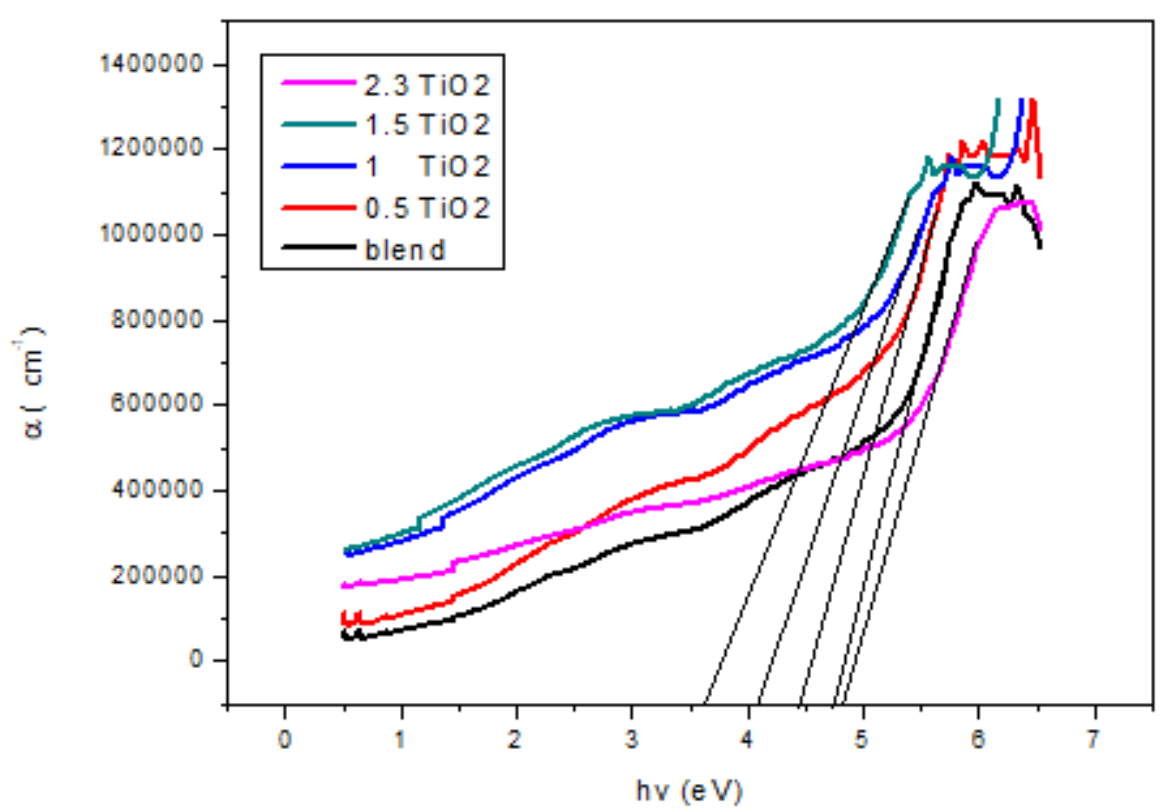

Figure 9

Absorption coefficients a as a function of hv for pure PANI/PMMA and nanocomposites films.

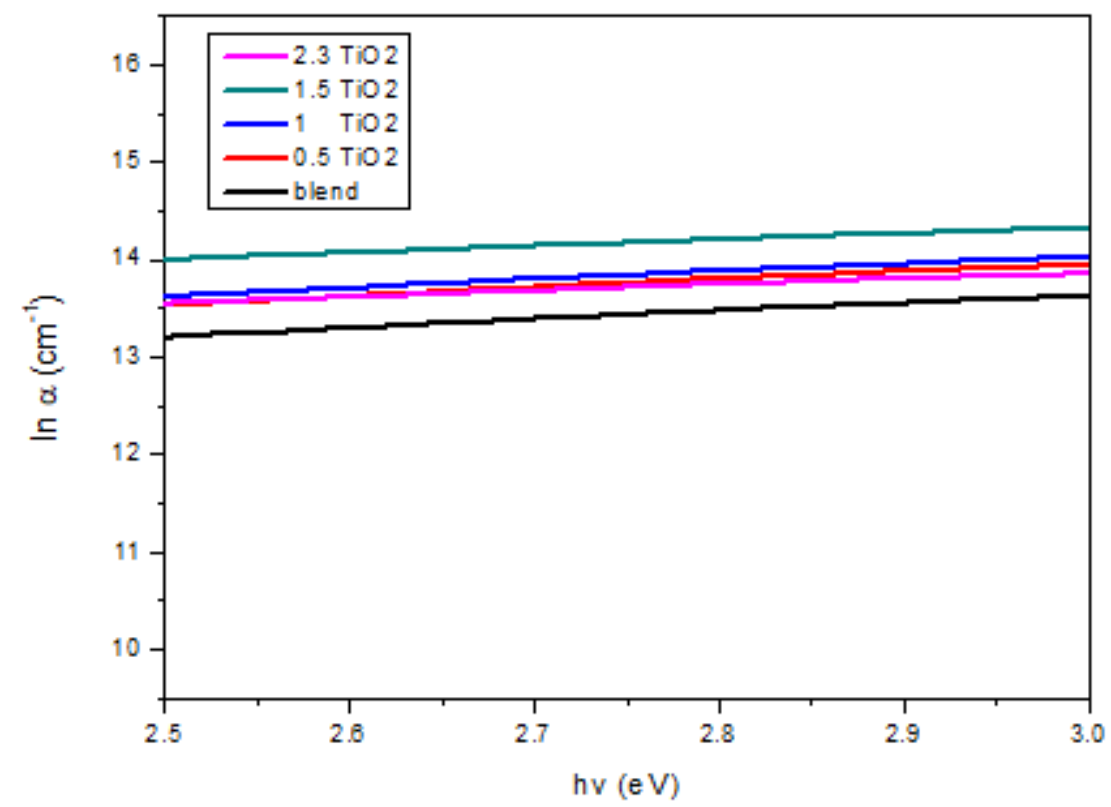

Figure 10

Absorption coefficient versus photon energy for pure PANI/SA and nanocomposites films. 


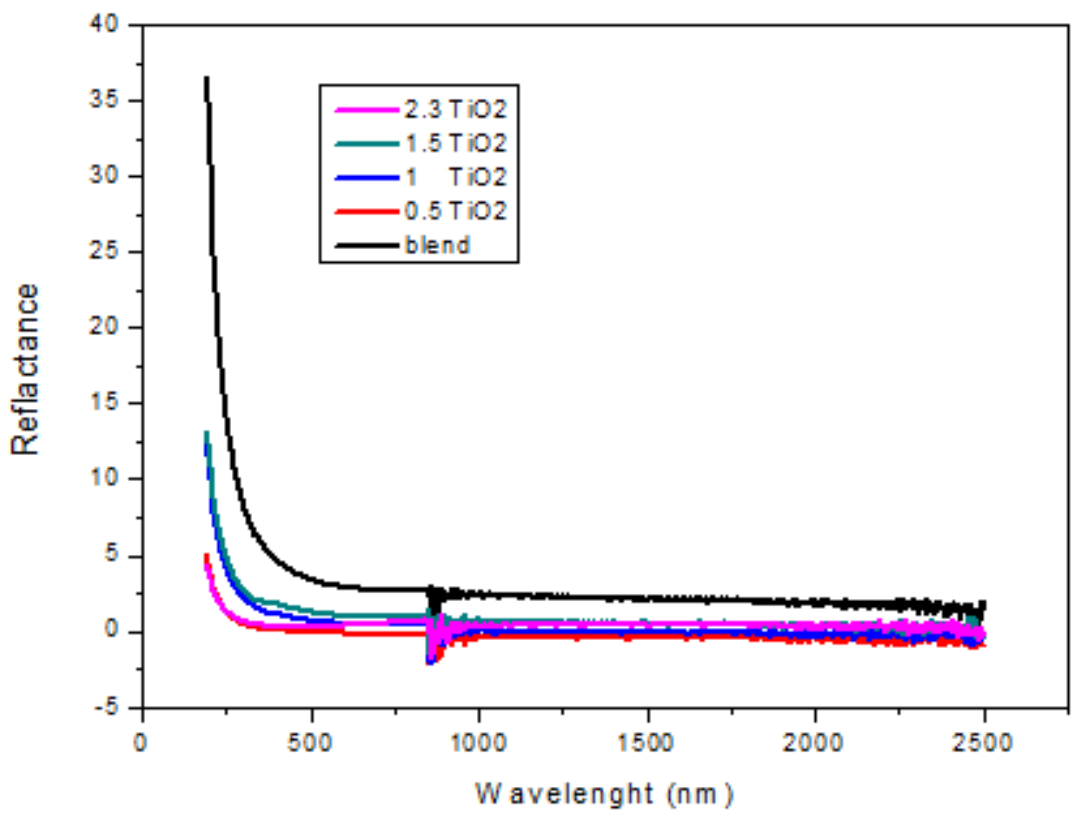

Figure 11

Reflectance (R) for pure PANI/PMMA and nanocomposite films. 

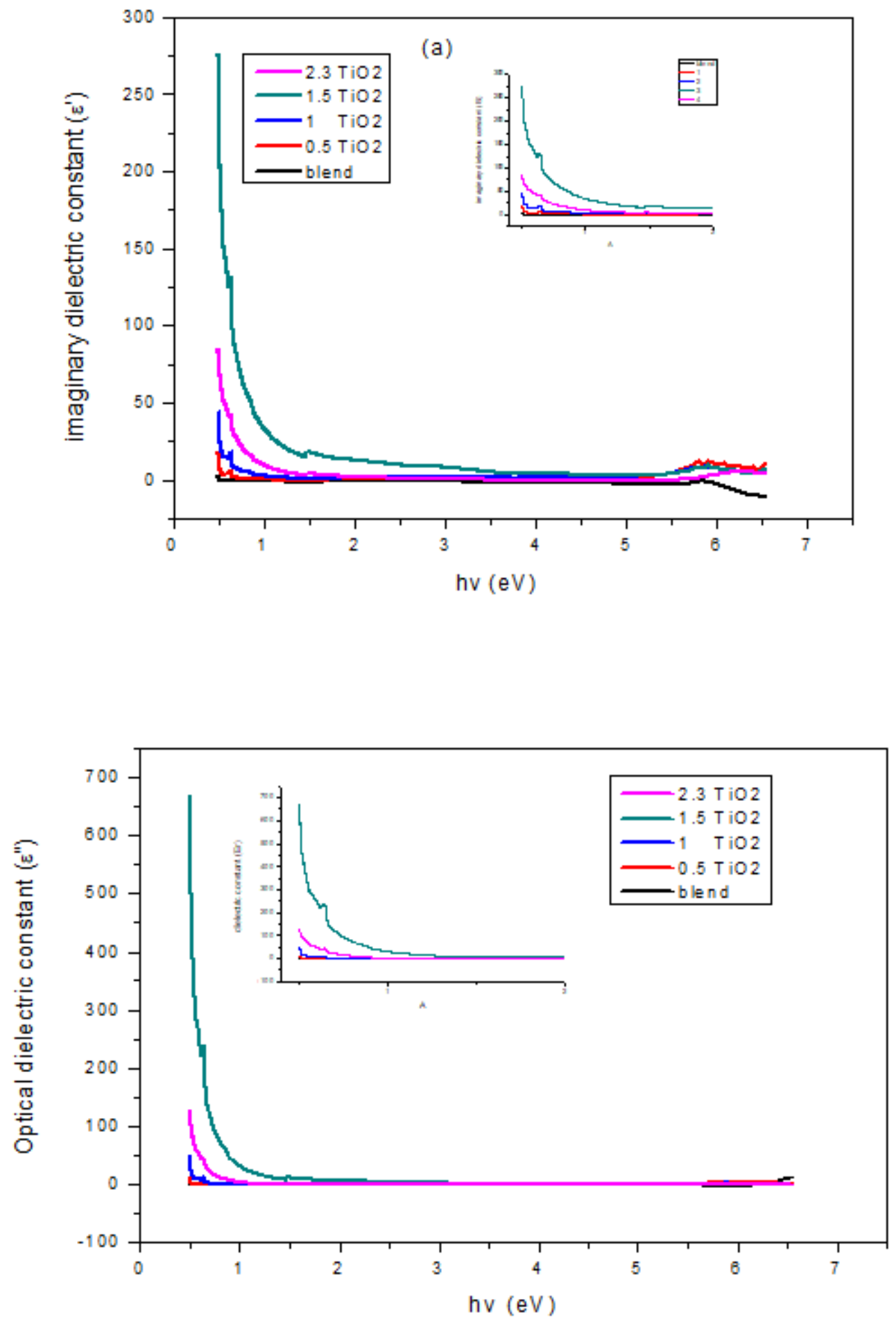

Figure 12

Variation of the (a) dielectric constant $\varepsilon^{\prime}$ and (b) dielectric loss $\varepsilon \rrbracket v \mathrm{vs}$. hv of the pure PANI/PMMA and nanocomposites films. 


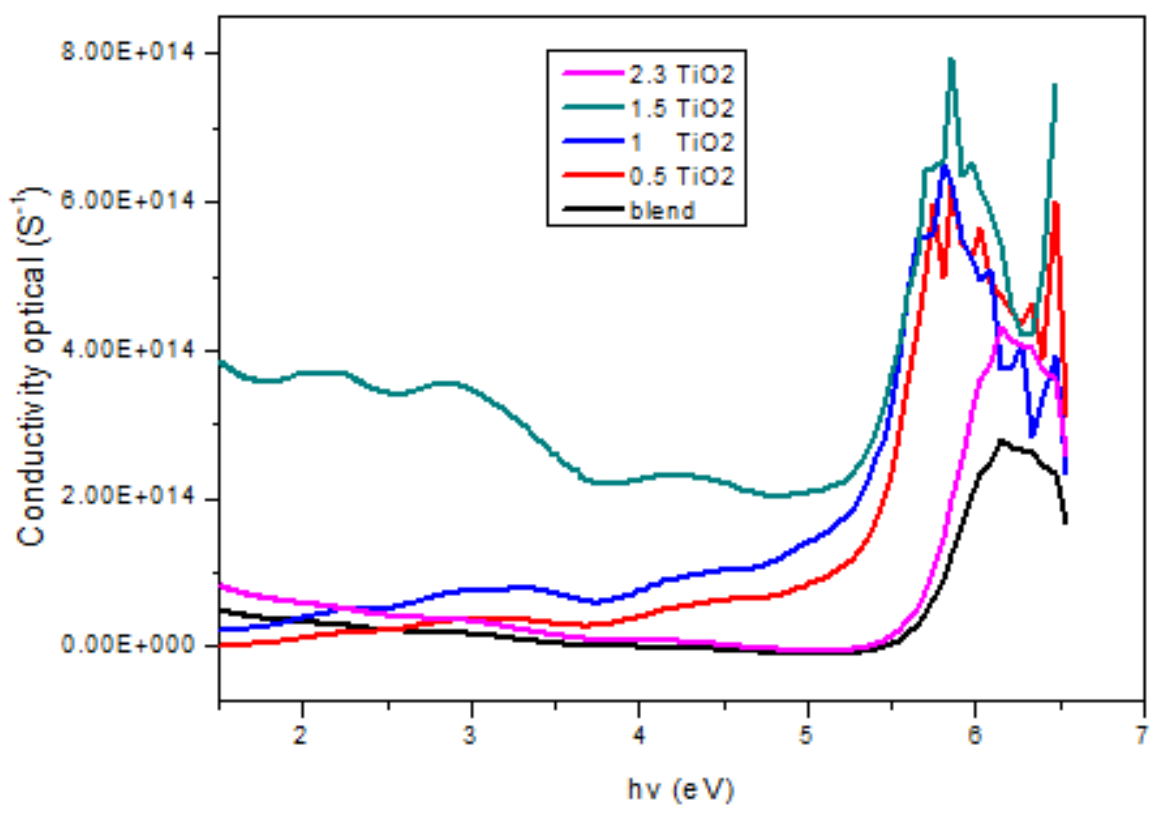

Figure 13

Variation of optical conductivity with photon energy for pure PANI/PMMA and nanocomposite films

\section{Supplementary Files}

This is a list of supplementary files associated with this preprint. Click to download.

- Scheme1.png 